\title{
Integration of Motivational Interviewing into Practice in the National Exercise Referral Scheme in Wales: A Mixed Methods Study
}

\author{
Graham F. Moore, Laurence Moore and Simon Murphy \\ Cardiff University, Wales
}

\begin{abstract}
Background: Though motivational interviewing (MI) has demonstrated efficacy in a range of behaviour change settings, effectiveness will require successful integration into everyday practice. This study examines implementers' views on delivering MI within an exercise referral scheme and consistency of consultations with MI before and after a 2-day workshop. Method: Semi-structured interviews were conducted with 27 exercise professionals and 10 area coordinators delivering the Welsh National Exercise Referral Scheme (NERS), and the MI trainer. Eleven professionals provided consultation recordings before and 6months after training, coded for fidelity using the Behaviour Change Counselling Index. Results: The workshop was well received by most, triggering increased recognition of potential motivational roles of consultations. However, some cited difficulties combining MI with structured data gathering activities, whilst a minority rejected MI, seeing current practice as effective, or MI as unnecessary because patients were ready to change. Although limited aggregate improvement in practice was observed, substantial improvements were observed in some individuals. Comments on the need for further practice or training were widespread. Conclusions: Efforts to implement MI should ensure that training and structures to provide monitoring and feedback are in place and that activities incorporated within consultations are compatible with MI delivery.
\end{abstract}

Keywords: Motivational interviewing, process evaluation, implementation, exercise referral.

\section{Introduction}

Motivational interviewing (MI), first described by Miller (1983), is "a collaborative, personcentred form of guiding to elicit and strengthen motivation for change" (Miller and Rollnick, 2009). Though originating in substance abuse treatment, its efficacy in a range of health behaviour domains is demonstrated by a number of systematic reviews (e.g. Resnicow, Davis and Rollnick, 2006; Rubak, Sandboek, Lauritzen and Christensen, 2005; Van Dorsten, 2007; VanWormer and Boucher, 2004). MI is increasingly being applied to physical activity promotion and of nine trials identified by a recent systematic review (Martins and McNeil, 2009), five reported significant short-term effects upon physical activity. However, only one reported 12-month outcomes, finding no sustained impacts (Harland et al., 1999). Hence, whilst short-term findings vary and long-term efficacy remains to be demonstrated, emerging

Reprint requests to Graham Moore, Cardiff Institute of Society and Health, School of Social Sciences, Cardiff University, 1-3 Museum Place, Cardiff CF10 3BD, Wales. E-mail: mooreg@ cardiff.ac.uk

(C) British Association for Behavioural and Cognitive Psychotherapies 2011 
evidence suggests that MI may in some circumstances offer utility in promoting physical activity.

In furthering this evidence base, an issue deserving careful consideration is whether interventions claiming to deliver MI actually do (Hecht et al., 2005). Miller and Rollnick (2009) comment that though diffusing rapidly into many domains, MI is often confused with other approaches, and delivered in a manner that violates its core spirit (Rollnick and Miller, 1995). Recent years have therefore seen growing attention to the development and application of scales to assess MI fidelity. The Motivational Interviewing Treatment Integrity (MITI) scale, for example, provides a tool for coding adherence to the spirit of MI and a range of core MI consistent techniques (Moyers, Martin, Manuel, Hendrickson and Miller, 2005; Pierson et al., 2007), facilitating scrutiny of how impacts differ by various dimensions of practitioner competence (e.g. Thyrian et al., 2007). The Behaviour Change Counselling Index (BECCI) provides a single fidelity score (Lane et al., 2005), offering a simple tool for providing feedback to practitioners.

Early trials of MI to promote physical activity (Brodie and Inoue, 2005; Harland et al., 1999; Hillsdon, Thorogood, White and Foster, 2002) mostly preceded the widespread dissemination of these measures, and hence reported no fidelity assessments. Whilst more recent trials describe quality control approaches such as reviews with implementers to discuss consultations (Befort et al., 2008; Bennett, Lyons, Winters-Stone, Nail and Sherer, 2007; Hardcastle, Taylor Bailey and Castle, 2008), the authors are aware of only three that quantify fidelity (Bennett, Young, Nail, Winters-Stone and Hanson, 2008; Carels et al., 2007; Greaves et al., 2008). Given that these trials mostly involved small numbers of self-selecting practitioners, delivering MI to establish its efficacy, greater control over delivery was likely achieved than might be the case in real-world interventions. However, it remains plausible that variable efficacy may at least in part reflect variable implementation and including fidelity assessment in such trials is good practice. Given that real-world interventions often involve delivery by multiple practitioners with limited counselling experience, close attention to fidelity perhaps becomes increasingly critical within pragmatic evaluations of their effectiveness.

In addition to growing attempts to examine whether MI is implemented, attention is also turning to the need to understand why. Miller and Rollnick (2009) describe a number of key barriers to implementation including the common misperception that MI is easy to learn. The authors describe requests to teach MI in 1-2 hour workshops as common, but as comparable to attempting to teach the viola over lunch. Two-day MI courses are increasingly common, although evidence is building that these too are insufficient to facilitate proficient use without ongoing support (Wahab, Menon and Szalacha, 2008). One study, for example, found that although a 2-day course convinced clinicians they had learned MI, practice samples showed insufficient change to benefit patients (Miller and Mount, 2001). Hence, research is increasingly attempting to identify the support needed to ensure that skills can be practised (Brug et al., 2007; Rubak, Sandbaek, Lauritzen, Borch-Johnsen and Christensen, 2009; Forsberg, Forsberg, Lindqvist and Helgason, 2010).

Whilst training commonly focuses upon providing knowledge, Madson, Loignon and Lane (2009) highlight a need to also consider issues such as self-efficacy, intention to use MI, attitudes and circumstances. Understanding practitioners' reactions to introductions to MI, and experiences of attempting to apply it to practice, may provide valuable insights into why implementation is more or less successful. To date, qualitative methods have perhaps 
been underused in understanding these issues. Whilst some studies report positive reactions amongst MI trainees via quantitative satisfaction measures (Broers et al., 2005; Lane, Johnson, Rollnick, Edwards and Lyons, 2003), in one qualitative study, healthcare providers saw MI as taking too long, whilst the passive role of the MI practitioner conflicted with perceived roles as information providers (Miller and Beech, 2009).

Data for this study are derived from a process evaluation within the pragmatic randomized controlled trial of the National Exercise Referral Scheme (NERS) in Wales, (Murphy et al., 2010). In addition to a 16-week exercise programme, NERS professionals delivered consultations on scheme entry and exit, with protocols stating that initial consultations would include motivational interviewing, alongside health assessments and goal setting. The scheme therefore offered a useful context in which to study a real-world attempt to integrate MI into the daily practice of exercise professionals, most of whom had not encountered it previously.

Early in the evaluation concerns regarding fidelity were raised by evaluators, given that MI had been taught via an initial 1-hour session. In response, the Welsh Assembly Government introduced 2-day courses. One-to-one consultations recorded before these courses were coded using BECCI, confirming inconsistency with MI . Whilst for the reasons described it may be naïve to hypothesize that MI would be delivered with high fidelity following 2-day training, this study combines qualitative interviews with area coordinators, exercise professionals and an MI training provider with longitudinal assessment of MI fidelity to examine: i) implementers' views on the acceptability and feasibility of using MI in practice following training; ii) whether practices began to move towards an MI consistent approach following training; and iii) the circumstances under which practices began to change.

\section{Method}

\section{Research design}

The study combines cross-sectional qualitative post-training interviews with longitudinal quantitative monitoring of MI delivery. An overview of the research design is presented in Figure 1. The study received ethical approval from an NHS research ethics committee.

\section{Sampling and participants}

Eligible participants for the qualitative aspect were 31 professionals attending one of three training courses between August 2008 and January 2009, of whom 27 took part. Professionals were fitness instructors who had undergone a level 3 exercise referral training course and were registered on the Register of Exercise Professionals (REPs). Additional interviews were conducted with all 10 area coordinators whose professionals attended this training, all of whom took part, and the MI training provider.

As ethical approval for consultation recordings was received after the August course, quantitative monitoring of consultation delivery focused upon professionals attending the October course $(n=23)$, of whom 14 provided baseline data, and 11 provided data at followup. Sampling details and flow of participants through the study are presented in Figure 1. 


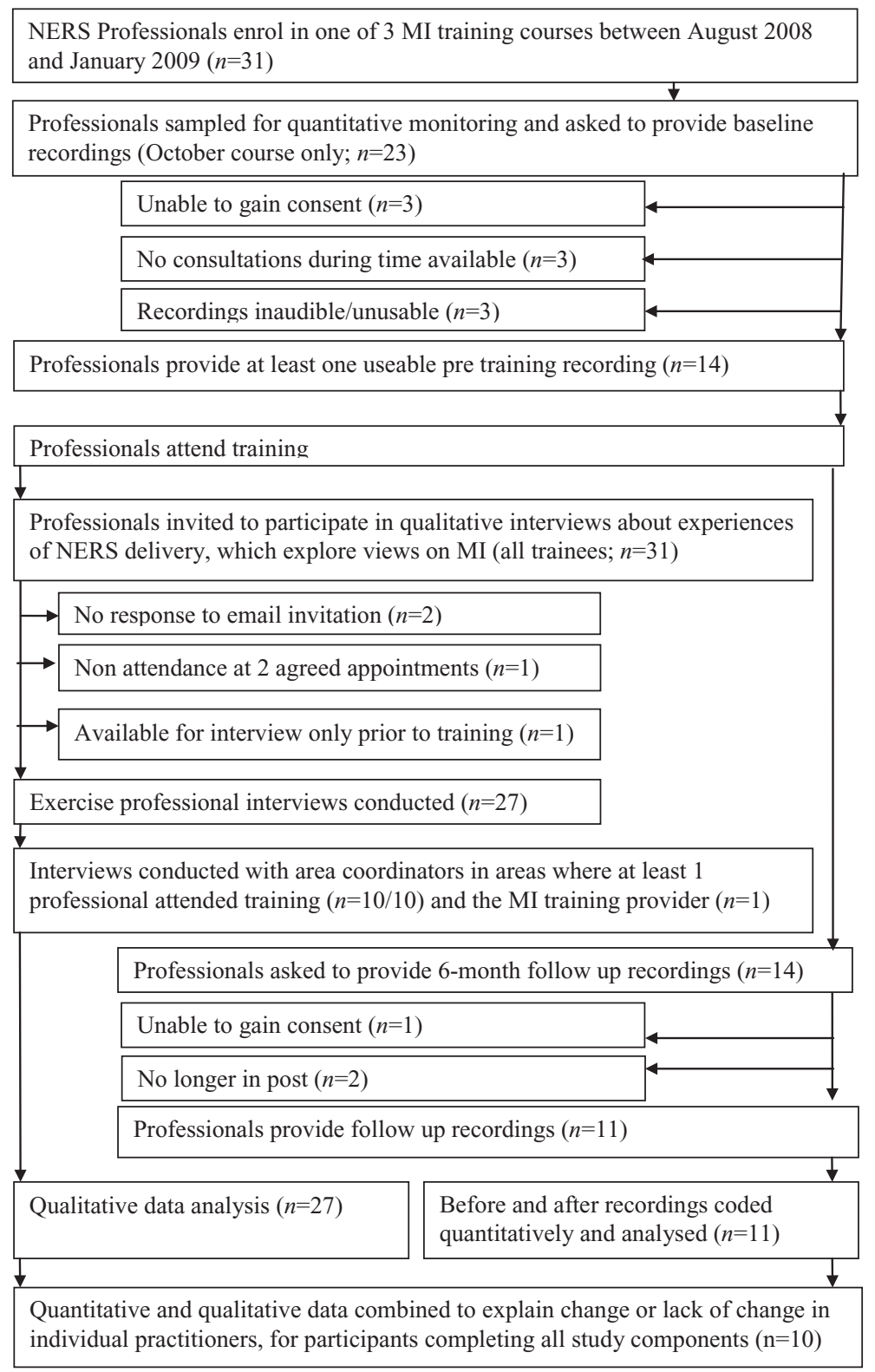

Figure 1. Overview of study design and flow of NERS exercise professionals through quantitative and qualitative aspects of the study

\section{Training}

All professionals attended a 2-day (approximately 13 hours) MI course combining brief presentations with demonstrations, video presentations, discussion, self-assessment, supervised practice, coaching and "real play" exercises. Professionals were asked to think of a 
behaviour they were ambivalent about, and given exercises in which they alternated between acting as patient or practitioner in order to gain experience of using MI strategies, whilst experiencing an insight from the patients' perspective about contrasts between MI consistent and non-consistent behaviours.

\section{Qualitative interviews: measures, data collection procedures and analysis}

Data collection. All professionals and coordinators were invited to participate by e-mail. After agreeing to take part, a time and date was arranged for a telephone interview (preferred to face-to-face interviews due to the geographical coverage of the national scheme) lasting up to an hour. Following e-mail contact from the evaluation team, the MI trainer offered to share his views having provided the training, and an interview was scheduled. Interviews were conducted by the lead author, who had previous contact with many study participants in meetings and earlier data collection phases. Interviews were recorded with the consent of the informant and transcribed verbatim.

Semi-structured interview schedules. Interviews were guided by schedules of open questions and topics. These were neither prescriptive nor-exhaustive, allowing the interviewer to explore issues of interest, whilst allowing interviewees to discuss issues not anticipated by the interviewer. Coordinator interviews, conducted as part of the wider evaluation, predominantly explored views on barriers and facilitators to delivering NERS and integration into local settings. Whilst not explicitly requesting views on MI, many coordinators volunteered opinions on training, speaking of its potential role within NERS. Exercise professional interviews were also conducted as part of the wider evaluation, exploring professionals' perceptions of their role within the programme, the scheme and barriers and facilitators of its implementation, scheme impacts on patient behaviour and mechanisms of change. For professionals attending the MI course, interviews also elicited perceptions of the purposes of one to one consultations, the extent to which professionals felt they used MI principles in their practice, and views on the adequacy of training provided. As the interview with the training provider was scheduled at the request of the interviewee, a loose structure was developed, exploring views on delivering training, professionals' responses to it, expectations for its impact, and perceived feasibility issues in integrating MI into NERS.

Analysis. A predominantly inductive thematic approach to analysis was adopted (Braun and Clarke, 2006), framed by a critical realist conceptualization of causality (Kazi, 2003), which focuses on how responses to and impacts of interventions are shaped by the perceptions and contextual circumstances of recipients, rather than simply whether interventions "work". Data were transcribed externally and the lead author checked transcription accuracy. Generation of codes began during accuracy checks, with each transcript subsequently coded using QSR Nvivo. Codes were applied to subsequent transcripts, with earlier transcripts revisited as new codes were generated. Themes were then identified and reviewed through rereading coded material and the full dataset. Qualitative analyses were completed prior to quantitative assessment of training impacts in order to minimize interpretation biases.

Coordinator data are described under a single code "Coordinator views on MI and its role within NERS", with verbatim quotes illustrating a range of views. Views of the MI training provider are then described under the heading "The MI training provider's views on the potential impacts of training on MI delivery in NERS". Due to difficulties preserving the anonymity of the training provider, the account of the interview as presented in this paper 
was e-mailed to the interviewee prior to inclusion, and approved as an accurate representation without changes. Key themes from exercise professional interviews related to: i) awareness of MI and the purpose of the first consultation before and after training; ii) perceived usefulness of training and impact on practice; and iii) implementation issues. Data from exercise professionals are described under each heading, with selected verbatim quotes illustrating a range of views.

\section{Quantitative study component: measures, data collection procedures and analysis}

Data collection procedures. GM supplied area coordinators with recording equipment and asked that professionals be requested to each record up to three consultations, and returned to collect recordings and accompanying consent forms at a time agreed with the coordinator. Procedures were repeated at 6-month follow-up.

MI fidelity. The first two useable recordings from each professional at each time point were coded by two independent coders using BECCI (Lane et al., 2005). Whilst MITI is considered the gold standard measure of MI fidelity (Moyers et al., 2005; Pierson et al., 2007), this requires substantial training, whereas training guidelines for BECCI were more achievable given the resources available for the study. Coders were psychology graduates who had previously attended a 2-day MI course. Instructions for training (Lane, 2005) were followed to prepare coders to use the measure. The measure demonstrated excellent inter-rater reliability ( $r=0.94$ pre training; $r=0.96$ post training). The mean score of coder 1 and coder 2 was used as the measure of MI fidelity. The final item asked coders to estimate whether professionals speak for more than half, about half, or less than half of the consultation time.

Statistical analysis. Means, standard deviations and medians for pre and post training fidelity were calculated and converted into percentages. As four professionals at baseline and two at follow-up provided only one recording, the first recording was used as the score for MI fidelity rather than an average of two or more scores. Spearman's rank correlation coefficients comparing first and second recordings for the seven professionals at baseline and the nine at follow-up who provided more than one recording indicated that MI adherence was typically stable between recordings ( $r=0.71$ and $r=0.87$ ). Significance of post-training changes was assessed using a Wilcoxon Sign test. Mean and standard deviation consultation lengths and frequencies for remaining consultation characteristics were calculated.

\section{Mixed method component}

Ten professionals provided quantitative before and after measures and qualitative data. Data sources were linked using a form of single-case design (Kazi, 2003), whereby quantitative change over time is tracked at the individual level and compared against qualitative responses to develop theories regarding why change may or may not have occurred. Qualitative data for each individual participant were coded into substrata of the thematic categories above and tabulated against change in practice. Participants were grouped into clusters by area and responses to training compared against those of their area coordinator. 
Table 1. Selected verbatim quotes from exercise coordinator interviews relating to perceptions of MI and its role within NERS

[D] We came back from that (MI) training thinking yes we could approach the consultations a lot better .... people have been referred by their doctor with 3 or 4 health conditions who haven't attended exercise for 15 years. . to manage those conditions and get them motivated is a big skill

$[\mathrm{H}]$ It was a pity we didn't have the motivational interviewing at the beginning because I think that has transformed a lot of how we all approach people. . I personally have never seen anything quite as amazing because, by asking some very simple questions and not being prescriptive. You know my history is being an instructor and instructors love to tell people what to do. Because that's why we became instructors. Whereas to really not to play lip service but to believe that every person knows exactly what they should be doing and they don't need you to tell them...I know for all my instructors who did the course they all feel exactly the same

[C] With the motivational interviewing it is a case of its identifying really why (the patient) has come. I think it took a long time for the instructors to actually grasp that, in the beginning, it's I mean, when you've done this kind of work for such a long time it's second nature, you don't realise you're doing it. I've asked people things and I just didn't realise that I don't know how I learnt to do that, it's just there.

[A] I've got to say I think our exercise referral professionals are very, very good at that aspect of their job. I think the MI training reinforced a lot of things they were doing was correct and they picked up a lot of new techniques and ideas that they could enforce... it was very worthwhile training, you know. But I think that is one area in our area that we do emphasize and I do emphasize as coordinator the importance of customer support, customer care, good communication

[G] Well one of our exercise professionals went on it first, she felt, well, she is very good at interviewing anyway, I had no problems with her. But I think one of our other professionals would benefit from doing it, I don't know whether it's a man thing, I don't know, I mean women relate to, I think we have a lot more patience and a lot more sort of understanding

[L] I know one of the reasons that it (MI training) was set up was to get people sort of adding more and working more on the goal setting but actually we were very good on the goal setting anyway, all of ours had short, medium and long term.

\section{Results}

\section{Coordinators' views on MI and its role within NERS}

A selection of verbatim quotes from coordinator interviews are presented in Table 1. Whilst three coordinators whose professionals received training in MI made no reference to its role when discussing how NERS affected behavioural change, and one discussed MI only when discussing views of training within the scheme, others commented that integration of MI offered substantial promise for NERS in their area. One, for example, commented that professionals had gained significant confidence dealing with patients with complex conditions through adopting MI principles. There was, however, substantial variability in perceptions of what MI was, and the roles that it might play in improving practice. Some saw its adoption as highly valuable, though necessitating a radical rethink of consultation structures, introducing principles that conflicted with prior practice. However, others saw MI as largely what instructors did anyway once they had been in the role for sufficient time, with training largely confirming the correctness of current practice, or as relevant only to professionals who 
were relatively poor communicators. MI was sometimes seen as a tool to enable professionals to extract information, or conflated with goal setting.

\section{The MI training provider's views on potential impacts of training on MI delivery in NERS}

The trainer commented that the course was well received by professionals, and that most appeared to see the value of change. However, the trainer also argued that the 2-day course "gives you intellectual insight but doesn't necessarily give you emotional insight such that you can easily change your practice". Real change was seen as requiring structures for selfreflection and further expert guidance, with the training provider arguing that "like with any new skill, you need to rehearse it, you need to get guidance, you need to get coaching and your confidence goes up then". In addition to a need for ongoing training to support integration, the training provider identified barriers to implementation relating to structures of NERS consultation, and professionals' perceptions of their role within these consultations, remarking that when asking professionals what they hoped to gain from the course, professionals consistently commented that "their job was collecting information. They were very clear that that was what their job was. . .they were very clear that what they hoped that we would teach them was how to be more efficient in doing that". This perception of the primacy of data collection was linked to a "genuine tension between the desire to collect data and what actually would help the person sat in front of you". The tendency to prioritize data collection over MI was seen as needing to be reversed, with the training provider arguing that if MI is to be integrated, professionals "have to think that this (MI) is the most important thing to do. You can collect the data at the end if the time is available". The training provider commented that once pressures of data collection were adhered to, time allowed for consultations lay at the outer margins of the minimum required to incorporate MI and that it "sets the wrong tempo for MI if you start off by saying, right I'm going to fill these forms in and ask you lots of questions".

\section{Professionals' views on the introduction to motivational interviewing}

Exercise professionals talk regarding the introduction to MI fell into three broad themes: awareness of MI and the purpose of the first consultation before and after training; perceived usefulness of training and impact on practice; and implementation issues. Each is described with selected quotes presented in Table 2 .

\section{Awareness of MI and the purpose of the first consultation before and after training}

Whilst typically recalling having touched on MI briefly in initial training, or sometimes not remembering having covered it at all, professionals commented that they had limited experience of MI prior to the 2-day course. In addition to increasing understandings of MI, some commented that training had made them aware of a disjuncture between how they had seen the purposes of the initial consultation and how its purposes had been conceived in the design stage by national implementers. Whilst professionals often commented on the value of the first consultation in allowing them to build rapport and put patients at ease, its primary purpose had sometimes been seen as one of form filling and information gathering. Some argued that introduction to MI had helped them move away from this view, towards seeing 
Table 2. Selected quotations from exercise professional interviews regarding perceptions of motivational interviewing following a 2-day course

Awareness of MI and the purpose of the first consultation before and after training

[C5] We had training a few weeks ago, regarding motivational interviewing, and it kind of opened, probably, most of our eyes, to what it was actually for. I think before we just thought it was a paper exercise where you just get everybody's details and go from there really, and just get them started up.

[C2] Before I thought our interviewing techniques were fine, you know, you just go through the form, get the relevant information, tell them about the scheme and get them started. But I think by doing that process it's definitely, I think, it cements something in that person then, to commit to doing something.
Perceived usefulness for practice

\section{Positive comments:}

[J39] Since we've come back from that course the way that we sort of speak to our clients has changed quite dramatically. . .instead of just asking question after question we sort of get them to sit there and they talk. Initially I thought no they're not going to talk but they do. They tell you the answers, you don't even need to ask the questions, they're already telling you it. ..I think you engage more with the clients.

[A8] You gained experience and you could see how it would work, rather than being told this is the procedure you should follow. It was more hands on and it gives you the confidence to go back and try it and adapt the methods to suit the individual as opposed to following a structure that you thought had to be followed. [A9] We've been on a motivational interviewing one, that was really good, about getting more, the most out of your initial consultations. Asking open questions, trying to get people to make their own decisions, you know trying to get them to weigh up the pros and cons and I thought that was really, really helpful.
Implementation issues

[J39] You do it on the course but it's putting it into practice we need to do now. . you feel almost embarrassed first of all.

[B32] The new skills they've tried to teach us on this course you know you couldn't do it with the present system we've got. ... the forms are a hindrance in a way to gaining what you want to gain from the client, which is change.

[L12] You need the time, because of the paperwork, you are going through the paperwork and you are going through the G-PAQ, you are going through all that and making sure everything is there, written down, everything is on the computer. . to do that type of interviewing you need time. 
Table 2. Continued

\begin{tabular}{|c|c|c|}
\hline $\begin{array}{l}\text { Awareness of MI and the purpose of the } \\
\text { first consultation before and after training }\end{array}$ & Perceived usefulness for practice & Implementation issues \\
\hline $\begin{array}{l}\text { [E19] Well um I, only about a month ago } \\
\text { I went on to the motivational } \\
\text { interviewing course, so possibly that } \\
\text { was a bit late coming ... but having } \\
\text { done that and knowing what they are } \\
\text { looking to achieve through the initial } \\
\text { assessment, my belief is, the main } \\
\text { reason they wanted to do that and I } \\
\text { believe it's right as well is to identify } \\
\text { what people, how people really feel } \\
\text { about exercise and their adherence to } \\
\text { try and keep them adhering to their } \\
\text { exercise throughout the } 16 \text { weeks. }\end{array}$ & $\begin{array}{l}\text { Negative comments: } \\
\text { [C17] With our clients, mostly a large percentage of them } \\
\text { are there anyway because they really want to be or they } \\
\text { have been asked to. So there is ambivalence there but it's } \\
\text { not restrictive kind of thing. } \\
\text { [F29] I weren't keen on it to be honest. It seemed like... I } \\
\text { could see where they were coming from, but it, I felt like if } \\
\text { I was in a psychiatrist's room and he was invading you } \\
\text { like, do you know. I didn't like it, I didn't like that [B34] I } \\
\text { found it boring and, personally and, I just didn't feel it } \\
\text { helped as there's only so much you can listen to obviously } \\
\text { as you're timescale and what you want from your client, } \\
\text { you want how they're feeling, what medication, what can } \\
\text { you do for them and then obviously you want to move on. } \\
\text { [L12] I did find the course difficult because like I say, I've } \\
\text { obviously, not set in my ways, maybe I have got a way of } \\
\text { working with my clients and it seems to work. }\end{array}$ & $\begin{array}{l}\text { [D23] I think with training like this, I } \\
\text { think it would be good if obviously like } \\
\text { if it was retrained and refreshed every } \\
\text { couple of say } 6 \text { or } 7 \text { months. } \\
\text { [G30] the only thing I found hard was } \\
\text { that we have to have the information } \\
\text { that we need to put on the database, } \\
\text { and how without asking questions do } \\
\text { we get that because it's not necessary } \\
\text { that they will actually give that } \\
\text { information, so I think I would really } \\
\text { really like to see the people who taught } \\
\text { it. I'd like to see them do a } \\
\text { consultation. }\end{array}$ \\
\hline
\end{tabular}


the consultation as an opportunity to elicit talk about change. Rejection of MI was however sometimes linked to maintenance of the view of consultations as being primarily for gathering information, and a perception that MI did not assist this task.

\section{Perceived usefulness of training and impacts on practice}

Most saw value in MI and spoke of a willingness to adopt MI. Some described how they had changed practices since training, often offering critical reflection on perceived shortcomings of previous practice. In some instances for example, professionals identified prior tendencies to ask closed questions and tell patients what they should do, which they felt had begun to alter after training. Through these changes, many commented that rapport and the amount of change talk had greatly improved. A minority however were unconvinced of the value of changing their practices, typically commenting either that current practice worked, or that as clients were already motivated to change, MI was unnecessary.

\section{Implementation issues}

Whilst some felt that the duration of training was adequate to facilitate practice, many commented that MI had yet to become normalized into practice, and that they would require time and practice to feel confident in using the skills. Hence, as with the MI training provider, the 2-day course was seen by some as the start of the road to implementing MI, but by no means as the end of it. In addition, some identified the tension between data collection and MI described by the training provider, commenting that structures of the initial consultation and the volume of data collection made integration of MI challenging. One professional, for example, expressed a desire for further clarification on how the two tasks could be integrated, whilst another commented that consultation structures would need to be radically rethought to integrate MI, with implicit value judgments and closed questions involved in data collection components clashing with its patient-centred spirit.

\section{Quantitative monitoring of MI delivery before and after training}

MI fidelity before and after training. As indicated in Table 3, mean MI fidelity for professionals providing both baseline and follow-up recordings increased slightly after training, although medians were lower at both time points, indicating an undue influence of small numbers of relatively high scores. A Wilcoxon Sign Test indicated that overall improvement in MI fidelity was not significant $(Z=.80, p=.42)$. At both timepoints, according to both coders, most professionals spoke more than half the time during consultation, whilst pre and post training consultations were of almost identical length, averaging approximately 35 minutes.

Explaining change in individual practitioners. Although there was little change at the aggregate level, at the individual level, seven professionals scored higher for MI fidelity after training, whilst four scored marginally lower. Whilst most changes were small, three demonstrated clear improvements, with fidelity increasing from below $10 \%$ at baseline to between 30 and $40 \%$ at follow-up. These professionals, and another who scored 4th highest at follow-up, all opened consultations with a 10-25 minute unstructured discussion of behaviour change, before completing measures. Two others opened by asking the patient to describe a 
Table 3. Characteristics of consultations before and after training

\begin{tabular}{llll}
\hline & & Before training & After training \\
\hline Percentage fidelity to MI & Mean $(S D)$ & $10.0(6.5)$ & $16.7(13.5)$ \\
& Median & 8.0 & 10.2 \\
Professionals speaking more than & $N(\%)$ coder 1 & $10(90.9)$ & $7(63.6)$ \\
half the time in consultations & & & \\
Consultation length in minutes & $N(\%)$ coder 2 & $9(81.8)$ & $7(63.6)$ \\
& Mean $(S D)$ & $35.2(12.8)$ & $34.7(17.2)$ \\
\hline
\end{tabular}

typical day, though moved on to structured data collections after about 5 minutes. In the remaining five, as typical of baseline consultations, talk about behaviour change occurred only during completion of structured questionnaires, with consultations placing substantial emphasis on didactic advice-giving.

Table 4 presents a matrix of sub-themes from interviews with each of the 10 professionals who provided quantitative longitudinal data and took part in a semi-structured interview. Notably, only in areas where the coordinator identified MI as a potentially valuable improvement over current practice did professionals consistently offer critical reflection on their own previous practice. Although two professionals in these areas scored only slightly higher after training, and another regressed to a lower level than at baseline, one in each area demonstrated improvements of $20 \%$ or more, with the five highest post-training fidelity scores from these three regions. In two areas where the coordinator did not mention MI when discussing how NERS helped patients become more active, negative views on the usefulness of training were expressed by professionals, with concerns regarding feasibility of integrating MI into current structures expressed in one. In both areas, no professional demonstrated change in practice, with three of the four lowest post-training fidelity scores coming from these two regions. In the remaining area, where the coordinator commented that training provided some useful additional techniques, but mostly reinforced existing practice, the sole professional providing recordings spoke positively of training, yet did not offer critical reflection on previous practice, with fidelity regressing to a lower level than at baseline. However, quantitative data were only obtained from one professional in this area, with the remaining professionals offering greater critical reflection.

Whilst overall stability between first and second recordings was high $(r=0.87)$, the only professionals whose practices demonstrated low stability were two of the three practitioners who performed highest at follow-up (the third provided only a single recording). Both, whilst maintaining higher than average MI fidelity in both consultations, scored more than $10 \%$ lower for second recordings than they did for first recordings. Hence, although demonstrating higher proficiency than at baseline, improvements appeared unstable across consultations.

\section{Discussion}

Limited initial MI training for NERS professionals appeared to contribute to both limited understandings of MI and tendencies for consultations to be seen primarily as data collection exercises. Following additional training, some described MI as having little to offer their practice, for reasons including maintenance of a view that data collection was the primary role 
Table 4. Cross tabulation of themes emerging from exercise professional and coordinator interviews against change in MI fidelity according to coding of pre and post training consultations for individual professionals

\begin{tabular}{|c|c|c|c|c|c|c|c|c|c|}
\hline \multirow[b]{3}{*}{ Area } & \multirow{3}{*}{$\begin{array}{c}\text { Area } \\
\text { coordinator } \\
\text { views }\end{array}$} & \multicolumn{6}{|c|}{ Exercise professional views } & \multirow[b]{3}{*}{$\begin{array}{l}\text { Change in } \\
\text { MI fidelity } \\
\text { score* }^{*}\end{array}$} & \multirow[b]{3}{*}{$\begin{array}{l}\text { Stability of } \\
\text { post } \\
\text { training } \\
\text { practice }^{* *}\end{array}$} \\
\hline & & \multirow{2}{*}{$\begin{array}{c}\begin{array}{c}\text { Role of } 1 \mathrm{st} \\
\text { consultation }\end{array} \\
\begin{array}{c}\text { Discussion of } \\
\text { changed }\end{array} \\
\text { perception of } \\
\text { role of } 1 \text { st } \\
\text { consultation }\end{array}$} & \multicolumn{3}{|c|}{ Perceived usefulness for practice } & \multicolumn{2}{|c|}{ Implementation issues } & & \\
\hline & & & $\begin{array}{l}\text { Positive } \\
\text { comments } \\
\text { regarding } \\
\text { usefulness for } \\
\text { practice }\end{array}$ & $\begin{array}{l}\text { Negative } \\
\text { comments } \\
\text { regarding } \\
\text { usefulness for } \\
\text { practice }\end{array}$ & $\begin{array}{l}\text { Critical reflection on } \\
\text { previous practice and } \\
\text { discussion of how MI } \\
\text { has been integrated } \\
\text { since training }\end{array}$ & $\begin{array}{l}\text { Concerns } \\
\text { regarding need } \\
\text { for practice or } \\
\text { training }\end{array}$ & $\begin{array}{l}\text { Feasibility } \\
\text { clash with } \\
\text { current } \\
\text { structures }\end{array}$ & & \\
\hline \multirow[t]{2}{*}{$\mathrm{C}$} & $\mathrm{X}$ & $\mathrm{X}$ & $\mathrm{X}$ & & $\mathrm{X}$ & $X$ & & + & High \\
\hline & & $\mathrm{X}$ & $\mathrm{X}$ & & $\mathrm{X}$ & $X$ & & +++ & Low \\
\hline A & & & $\mathrm{X}$ & & & $\mathrm{X}$ & & - & High \\
\hline \multirow[t]{2}{*}{$\mathrm{E}$} & & & & $\mathrm{X}$ & & & & + & High \\
\hline & & & $\mathrm{X}$ & & & & $X$ & - & High \\
\hline \multirow[t]{2}{*}{$\mathrm{D}$} & $\mathrm{X}$ & $\mathrm{X}$ & $\mathrm{X}$ & & $X$ & & & +++ & Low \\
\hline & & & $X$ & & $\mathrm{X}$ & $X$ & & - & High \\
\hline $\mathrm{F}$ & & & & $\mathrm{X}$ & & & & - & Moderate \\
\hline \multirow[t]{2}{*}{$\mathrm{J}$} & $\mathrm{X}$ & & $\mathrm{X}$ & & $\mathrm{X}$ & $X$ & & + & $\mathrm{n} / \mathrm{a}$ \\
\hline & & & $X$ & & $X$ & & & ++++ & $\mathrm{n} / \mathrm{a}$ \\
\hline
\end{tabular}

* - no improvement, + 0-10\% improvement, $++10-20 \%$ improvement, $+++20-30 \%$ improvement, $++++>30 \%$ improvement

** low stability $>10 \%$ discrepancy between recording one and two, moderate $5-10 \%$ discrepancy between recording one and two, high $<5 \%$ discrepancy between recording one and two, n/a only one recording provided 
of consultations or that current practice was effective. However, most described a willingness to adopt MI, sometimes commenting that perceptions of the role of the consultation had begun to change after further training. For many, increased understanding of the value of MI, and perceived impact of initial attempts to use MI on rapport with patients appeared to trigger substantial critical reflections on previous practices such as unsolicited advicegiving. However, consistent with growing evidence that putting MI into practice requires skills development beyond a 2-day course (Forsberg et al., 2010). professionals and the training provider described a need for practice or further training, whilst further concerns were raised about the compatibility of consultations with MI. These averaged 35 minutes, including a substantial data gathering element that reduced the time available for MI, with structured questioning and implicit value judgments within lifestyle questionnaires seen by some as incompatible with MI.

Hence, despite largely positive perceptions of MI following the course, 6-months after training no significant change in MI fidelity was observed. Fidelity scores at both time-points were comparable to recent assessments of GPs' routine practice using the same scale (Moran, Bekker and Latchford, 2008). However, several individuals did demonstrate movement towards an MI consistent approach. Whilst time allowed for change talk was still very short, these professionals prioritized discussion of behavioural change over data gathering, allowing time for this prior to completing measures. However, most still emphasized formfilling, dedicating little or no time to unstructured change talk. Improvements occurred only in areas headed by coordinators who commented on the potential value of integrating MI into practice after training and where all professionals expressed positive views on training, consistent with a view that transferring training into practice is easier where colleagues are supportive of integration (Baldwin and Ford, 1988). However, practice remained variable between professionals within areas where support appeared unanimous.

Strengths of this study include use of a validated MI fidelity assessment tool (Lane et al., 2005) and integration of qualitative data into before and after fidelity assessment, offering explanations for training impacts. However, weaknesses include that recording consultations may have led to Hawthorne effects (Campbell, Maxey and Watson, 1995). Whilst several recordings per professional would ideally have been obtained, data collection was restricted by the limited time between receipt of ethical approval and implementation of training. The small sample limited power, although statistical significance was not of primary importance to this study. Responses to qualitative interviews were perhaps influenced by the interviewer's links to the wider evaluation, although nesting discussion of MI training into wider discussions of implementation probably made the aims of this particular sub-study less explicit. Although the training provider confirmed the accuracy of the account of their interview, it was not possible to circulate analyses to coordinators and professionals. Convergence between views of the training provider and those of professionals, analyzed prior to the training provider interview, adds credibility to the accounts. Finally, face-to-face interaction may have led to understandings missed by using the telephone, although the anonymity of telephone interviews may have elicited more open responses.

Nevertheless, the study has important implications for programmes aiming to deliver MI. Such programmes should consult with experts in MI on baseline training requirements, ensuring that implementers have adequate skills and understanding of MI prior to commencing practice, and allowing communication of primary functions of consultations throughout the system. Facilitating delivery by professionals with no counselling background 
and who are perhaps accustomed to more didactic approaches to promoting change possibly requires greater investment than when $\mathrm{MI}$ is delivered by self-selected practitioners with counselling experience. Implementation was perhaps made difficult within NERS by the fact that professionals were experienced in schemes not using MI, and had a year working within NERS before the expectation of MI delivery was reinforced through in-depth training. Asking professionals to adopt MI will require them to accept it as an improvement on current practice (Spillane, Reiser and Reimer, 2002); a position most, though not all, appeared to accept. Miller and Rose (2009) have compared the process of guiding practitioners towards changing their practice to the process of guiding patients in changing their behaviour. Just as instructing a patient to change may undermine autonomy and self-esteem, causing defence of current behaviour (Brehm, 1966), practitioners may interpret instruction to change as criticism and a threat to professional autonomy, leading to defence of current practice (Spillane et al., 2002), with MI unlikely to be adopted successfully by the minority of professionals who saw little value in it. Hence, as well as providing training at the earliest opportunity, willingness to adopt MI should be ascertained during staff recruitment, with MI forming part of professionals' job description.

Furthermore, additional support is needed to translate widespread willingness to adopt MI into ability to practice (Madson et al., 2009). Progress towards an MI consistent approach may require integration of mechanisms for critical self-reflection, monitoring and feedback (Bennett, Moore, et al., 2007; Miller, Yahne, Moyers, Martinez and Pirritano, 2004; Mitcheson, Bhavsar and McCambridge, 2009; Smith et al., 2007) both to provide support to those recognizing a need for it, and to prevent practitioners from prematurely believing they have become competent (Miller and Mount, 2001). Where coordinators are new to MI, monitoring and feedback structures should be contracted to external parties with expertise in MI. As demonstrated by this paper, use of mixed-method evaluation designs that quantitatively monitor the effectiveness of efforts to implement MI, whilst qualitatively exploring barriers and facilitators to putting MI into practice, may be substantially more useful in informing practice than mono-method approaches.

Finally, consultation structures must be considered carefully. First, consultations must allow sufficient time for MI. Second, MI will often not be the sole purpose of the consultation, and consideration needs to be given to whether implementers are being asked to combine MI with activities with which it is incompatible. Structured assessments pose challenges in that they risk rendering the patient passive, contrary to the patient-centred spirit of MI. If assessments need to be conducted alongside MI, the manner in which these tasks are to be integrated merits careful consideration (Rollnick, Miller and Butler, 2008).

\section{Acknowledgements}

GM led the process evaluation design, collected data, conducted analyses and drafted the paper. SM project managed the evaluation of which the process evaluation was a part, and advised on process evaluation design. All authors commented on drafts and approved the final manuscript. The authors would like to thank the NERS evaluation team, the scheme's coordinators Elaine McNish and Jeannie Wyatt-Williams, as well as Janine Hale and Chris Roberts within the Public Health Research Branch of the Welsh Assembly Government for facilitating and supporting the evaluation study. In addition, we would like to thank Professor Stephen Rollnick for advice and comments on drafts of the manuscript, Dr Claire Lane for 
providing the BECCI scale, advising on its use and providing training materials to prepare coders for its use and for advice and comments on drafts of the manuscript, and Eleri Sian Jones for assistance with coding of MI recordings. We would also like to thank the Welsh Assembly Government for funding the evaluation and all exercise coordinators and professionals and the motivational interviewing training provider who took part in the study. The lead author was supported by a studentship from the Economic and Social Research Council [PTA-031-2006-00086].

\section{References}

Baldwin, T. and Ford, J. (1988). Transfer of training: a review and directions for research. Personnel Psychology, 41, 63-104.

Befort, C. A., Nollen, N., Ellerbeck, E. F., Sullivan, D. K., Thomas, J. L. and Ahluwalia, J. S. (2008). Motivational interviewing fails to improve outcomes of a behavioral weight loss program for obese African American women: a pilot randomized trial. Journal of Behavioral Medicine, 31, 367-377.

Bennett, G. A., Moore, J., Vaughan, T., Rouse, L., Gibbins, J. A., Thomas, P., et al. (2007). Strengthening Motivational Interviewing skills following initial training: a randomised trial of workplace-based reflective practice. Addictive Behaviors, 32, 2963-2975.

Bennett, J. A., Lyons, K. S., Winters-Stone, K., Nail, L. M., and Scherer, J. (2007). Motivational interviewing to increase physical activity in long-term cancer survivors: a randomized controlled trial. Nursing Research, 56, 18-27.

Bennett, J. A., Young, H. M., Nail, L. M., Winters-Stone, K. and Hanson, G. (2008). A telephoneonly motivational intervention to increase physical activity in rural adults: a randomized controlled trial. Nursing Research, 57, 24-32.

Braun, V. and Clarke, V. (2006). Using thematic analysis in psychology. Qualitative Research in Psychology, 3, 77-101.

Brehm, J. W. (1966). A Theory of Psychological Reactance. New York: Academic Press.

Brodie, D. A. and Inoue, A. (2005). Motivational interviewing to promote physical activity for people with chronic heart failure. Journal of Advanced Nursing, 50, 518-527.

Broers, S., Smets, E., Bindels, P., Evertsz, F. B., Calff, M. and de Haes, H. (2005). Training general practitioners in behavior change counseling to improve asthma medication adherence. Patient Education and Counseling, 58, 279-287.

Brug, J., Spikmans, F., Aartsen, C., Breedveld, B., Bes, R. and Fereira, I. (2007). Training dieticians in basic motivational interviewing skills results in changes in their counseling style and in lower saturated fat intakes in their patients. Journal of Nutrition Education and Behavior, 39, 8-12.

Campbell, J. P., Maxey, V. A. and Watson, W. A. (1995). Hawthorne effect: implications for prehospital research. Annals of Emergency Medicine, 26, 590-594.

Carels, R. A., Darby, L., Cacciapaglia, H. M., Konrad, K., Coit, C., Harper, J., et al. (2007). Using motivational interviewing as a supplement to obesity treatment: a stepped-care approach. Health Psychology, 26, 369-374.

Forsberg, L., Forsberg, L., Lindqvist, H. and Helgason, A. (2010). Clinician acquisition and retention of Motivational Interviewing skills: a two-and-a-half-year exploratory study. Substance Abuse Treatment, Prevention, and Policy, 5, 8.

Greaves, C. J., Middlebrooke, A., O'Loughlin, L., Holland, S., Piper, J., Steele, A., et al. (2008). Motivational interviewing for modifying diabetes risk: a randomised controlled trial. British Journal of General Practice, 58, 535-540.

Hardcastle, S., Taylor, A., Bailey, M. and Castle, R. (2008). A randomised controlled trial on the effectiveness of a primary health care based counselling intervention on physical activity, diet and CHD risk factors. Patient Education and Counseling, 70, 31-39. 
Harland, J., White, M., Drinkwater, C., Chinn, D., Farr, L. and Howel, D. (1999). The Newcastle exercise project: a randomised controlled trial of methods, to promote physical activity in primary care. British Medical Journal, 319, 828-832B.

Hecht, J., Borrelli, B., Breger, R. K. R., DeFrancesco, C., Ernst, D. and Resnicow, K. (2005). Motivational interviewing in community-based research: experiences from the field. Annals of Behavioral Medicine, 29, 29-34.

Hillsdon, M., Thorogood, M., White, I. and Foster, C. (2002). Advising people to take more exercise is ineffective: a randomized controlled trial of physical activity promotion in primary care. International Journal of Epidemiology, 31, 808-815.

Kazi, M. (2003). Realist Evaluation for Practice. British Journal of Social Work, 33, 803-818.

Lane, C. (2005). The Behaviour Change Counselling Index (BECCI): manual for coding behaviour change counselling. From http://www.cardiff.ac.uk/sonms/resources/20020930BECCIManual.doc

Lane, C., Huws-Thomas, M., Hood, K., Rollnick, S., Edwards, K. and Robling, M. (2005). Measuring adaptations of motivational interviewing: the development and validation of the behavior change counseling index (BECCI). Patient Education and Counseling, 56, 166173.

Lane, C., Johnson, S., Rollnick, S., Edwards, K. and Lyons, M. (2003). Consulting about lifestyle change: evaluation of a training course for specialist diabetes nurses. Practical Diabetes International, 20, 204-208.

Madson, M. B., Loignon, A. C. and Lane, C. (2009). Training in motivational interviewing: a systematic review. Journal of Substance Abuse Treatment, 36, 101-109.

Martins, R. K. and McNeil, D. W. (2009). Review of Motivational Interviewing in promoting health behaviors. Clinical Psychology Review, 29, 283-293.

Miller, S. T. and Beech, B. M. (2009). Rural healthcare providers question the practicality of motivational interviewing and report varied physical activity counseling experience. Patient Education and Counseling, 76, 279-282.

Miller, W. R. (1983). Motivational Interviewing with problem drinkers. Behavioural Psychotherapy, $11,147-172$.

Miller, W. R. and Mount, K. A. (2001). A small study of training in motivational interviewing: does one workshop change clinician and client behavior? Behavioural and Cognitive Psychotherapy, 29, 457-471.

Miller, W. R. and Rollnick, S. (2009). Ten things that motivational interviewing is not. Behavioural and Cognitive Psychotherapy, 37, 129-140.

Miller, W. R. and Rose, G. R. (2009). Toward a theory of motivational interviewing. American Psychologist, 64, 527-537.

Miller, W. R., Yahne, C. E, Moyers, T. B., Martinez, J. and Pirritano, M. (2004). A randomized trial of methods to help clinicians learn motivational interviewing. Journal of Consulting and Clinical Psychology, 72, 1052-1062.

Mitcheson, L., Bhavsar, K. and McCambridge, J. (2009). Randomized trial of training and supervision in motivational interviewing with adolescent drug treatment practitioners. Journal of Substance Abuse Treatment, 37, 73-78.

Moran, J., Bekker, H. and Latchford, G. (2008). Everyday use of patient-centred, motivational techniques in routine consultations between doctors and patients with diabetes. Patient Education and Counseling, 73, 224-231.

Moyers, T. B., Martin, T., Manuel, J. K., Hendrickson, S. M. L. and Miller, W. R. (2005). Assessing competence in the use of motivational interviewing. Journal of Substance Abuse Treatment, 28, 19 26.

Murphy, S., Raisanen, L., Moore, G., Edwards, R., Linck, P., Williams, N., et al. (2010). A pragmatic randomised controlled trial of the Welsh National Exercise Referral Scheme: protocol for trial and integrated economic and process evaluation. BMC Public Health, 10, 352. 
Pierson, H. M., Hayes, S. C., Gifford, E. V., Roget, N., Padilla, M., Bissett, R., et al. (2007). An examination of the Motivational Interviewing Treatment Integrity code. Journal of Substance Abuse Treatment, 32, 11-17.

Resnicow, K., Davis, R. and Rollnick, S. (2006). Motivational interviewing for pediatric obesity: conceptual issues and evidence review. Journal of the American Dietetic Association, 106, 2024 2033.

Rollnick, S. and Miller, W. R. (1995). What is motivational interviewing? Behavioural and Cognitive Psychotherapy, 23, 325-334.

Rollnick, S., Miller, W. R. and Butler, C. C. (2008). Motivational Interviewing in Health Care. New York: Guilford Press.

Rubak, S., Sandbaek, A., Lauritzen, T., Borch-Johnsen, K., and Christensen, B. (2009). General practitioners trained in motivational interviewing can positively affect the attitude to behaviour change in people with type 2 diabetes. Scandinavian Journal of Primary Health Care, 27, 172-179.

Rubak, S., Sandboek, A., Lauritzen, T. and Christensen, B. (2005). Motivational interviewing: a systematic review and meta-analysis. British Journal of General Practice, 55, 305-312.

Smith, J. L., Amrhein, A. P., Brooks, A. C., Carpenter, K. M., Levin, D., Schreiber, E. A., et al. (2007). Providing live supervision via teleconferencing improves acquisition of motivational interviewing skills after workshop attendance. The American Journal of Drug and Alcohol Abuse, 33, $163-168$.

Spillane, J. P., Reiser, B. J. and Reimer, T. (2002). Policy implementation and cognition: reframing and refocusing implementation research. Review of Educational Research, 72, 387-431.

Thyrian, J. R., Freyer-Adam, J., Hannover, W., Roske, K., Mentzel, F., et al. (2007) Adherence to the principles of Motivational Interviewing, clients' characteristics and behavior outcome in a smoking cessation and relapse prevention trial in women postpartum. Addictive Behaviors, 32, 2297-2303.

Van Dorsten, B. (2007). The use of motivational interviewing in weight loss. Current Diabetes Reports, 7, 386-390.

Van Wormer, J. J. and Boucher, J. L. (2004). Motivational Interviewing and diet modification: a review of the evidence. The Diabetes Educator, 30, 404-419.

Wahab, S., Menon, U. and Szalacha, L. (2008). Motivational interviewing and colorectal cancer screening: a peek from the inside out. Patient Education and Counseling, 72, 210-217. 